\title{
Genetic hyperferritinemia without iron overload
}

INSERM

\section{Source}

INSERM. (1999). Orphanet: an online rare disease and orphan drug data base. Genetic hyperferritinemia without iron overload. ORPHA:254704

Genetic hyperferritinemia without iron overload is a rare biological anomaly defined as high serum ferritin levels without elevations of transferrin saturation, tissue or serum iron and characterized by an apparently asymptomatic clinical phenotype. 